IADIS International Journal on WWW/Internet

Vol. 18, No. 1, pp. 121-138

ISSN: $1645-7641$

\title{
SMART CITIES IN RESEARCH: STATUS-QUO AND FUTURE RESEARCH DIRECTIONS
}

\author{
Yusuf Bozkurt, Reiner Braun, Alexander Rossmann and Dieter Hertweck \\ Department of Computer Science, Reutlingen University, 72762 Reutlingen, Germany
}

\begin{abstract}
The shift of populations to cities is creating challenges in many respects, thus leading to increasing demand for smart solutions of urbanization problems. Smart city applications range from technical and social to economic and ecological. The main focus of this work is to provide a systematic literature review of smart city research to answer two main questions: (1) How is current research on smart cities structured? and (2) What directions are relevant for future research on smart cities? To answer these research questions, a text-mining approach is applied to a large number of publications. This provides an overview and gives insights into relevant dimensions of smart city research. Although the main dimensions of research are already described in the literature, an evaluation of the relevance of such dimensions is missing. Findings suggest that the dimensions of environment and governance are popular, while the dimension of economy has received only limited attention.
\end{abstract}

\section{KEYWORDS}

Smart City, Literature Review, Text-Mining, Environment, Governance, Economy

\section{INTRODUCTION}

The shift of populations to cities and urban-dense areas is creating challenges in many respects. Cities play a major role in social and economic development worldwide. Therefore, they are key elements for sustainable development in the future (Mori \& Christodoulou, 2012). Research on cities has developed rapidly in recent years, and the term "smart city" is often used, but what makes a city smart, and how is it defined?

A review of the literature makes it clear that there is no common definition of what a smart city is. Some definitions focus on information and communication technologies (ICTs) as drivers and enablers of sustainable development, while others focus more on socio-economic, governance, and multi-stakeholder aspects (Albino et al., 2015). Perspectives on smart cities range from technical and social to economic and ecological. Depending on whether the perspective is on urban planning, ICT, energy, mobility, governance, or economy, the definition 
IADIS International Journal on WWW/Internet

of a smart city can differ in multiple ways. However, synonyms such as intelligent, virtual, knowledge, sustainable, talented, wired, digital, and eco are often used to describe smart cities (Albino et al., 2015; Catriona et al., 2014). Exploring the concept of a smart city, Lombardi et al. (2012) focused on the production of knowledge and the development of innovations. The main focus of smart city research is on the role of human capital/education, social and relational capital, and environmental issues, all of which are important drivers of urban growth (Lombardi et al., 2012). A precise and general definition of a smart city is still missing, but main dimensions of research are already visible and described in some literature (Caragliu et al., 2011; Giffinger et al., 2010). With this structure, the current main dimensions of smart city research can be classified into six areas: smart governance, smart economy, smart environment, smart people, smart living, and smart mobility (Catriona et al., 2014; Giffinger et al., 2010). Despite this raw structure of smart city research, the current state of the art on each of the six dimensions and precise directions for future research on smart city research remains vague. Therefore, future research should investigate how theoretical models can be applied to specific implementation cases. Consequently, this paper focuses on the following two research questions:

RQ1: How is the current research in the area of smart cities structured?

$R Q 2:$ What directions for further research are relevant within this structure?

We apply a systematic literature review to answer these questions. Thus, we use text-mining methods to analyze a large number of research articles in a systematic way. This approach leads to the identification of the most relevant publications in the field and gives relevant insights into the state of the art on each research dimension.

This paper is an extended version of Bozkurt et al., 2020 and provides more details especially in related work and the conducted text-mining analysis. It is structured as follows: First of all, an overview of existing literature reviews on smart cities is given. After positioning this paper in contrast to existing work, details on the conducted research methodology are presented. This is followed by the results of the text-mining analysis, the mapping of smart city topics to the smart city dimensions, as well as an analysis of the popularity of each dimension in smart city research. Subsequently, the research stream in each smart city dimension is discussed. Next, further research directions and limitations of this work are pointed out in the discussion section; and finally a conclusion is given.

\section{RELATED WORK}

Different studies on smart city literature reviews are available in the scientific literature. Therefore, we analyzed relevant related work to clarify our position in existing research. Table 1 summarizes the identified literature reviews on smart cities, the used databases, time horizons of reviewed papers, exlussion process, the applied methods, search restrictions and the main focus of the review.

In contrast to existing literature reviews, this research captures a holistic view on the broad research area of smart cities. It presents a high-level summary of smart city research and clusters the topics in well-known and accepted dimensions for smart city research. Although some main dimensions are already described in literature, to date, research has not evaluated the popularity 
of such dimensions. To do so, we created a ranking for the different dimensions of smart city research. Additionally, further research directions for each smart city dimension are discussed. Moreover, our methodology differs from other literature reviews, as we used text-mining to glean insights from a significantly larger set of papers (e.g. ranking and structure of smart city dimensions).

Table 1. Overview of relevant literature reviews on smart cities

\begin{tabular}{l} 
Authors / Database (D) / Time (T) and Exclusion (E) process \\
and number of publications \\
\hline Colding \& Barthel, 2017 \\
D - Scopus \\
T - Search A - date of search January 12, 2017. \\
$\boldsymbol{T}$ - Search B - date of search October 27, 2016 \\
$\boldsymbol{E}$ - Search A 6670 hits and Search B 7 hits
\end{tabular}

Purnomo \& Prabowo, 2016

D - Science Direct; ACM Digital Library, IEEE Xplore, Google Scholar

$\boldsymbol{T}$ - 2004 - September 2015

$\boldsymbol{E}$ - 1. Initial search; $N=301$ : Includes the limit scope, determining the research question, the search process which involves the selection of literature sources and keywords, inclusion and exclusion criteria and the data extraction of selected papers to be explored further.

2. Abstract analysis; $N=177$ : Carrying out the study based on demographics to determine the trends and characteristics: (1) publishing outlets, (2) most prolific authors, (3) most productive institutions, (4) authors' academic backgrounds, (5) publication trends, (6) background of authors, (7) university affiliation based on country, (8) researched industries and countries, (9) researched institution size.

3. Forward/backward search; N=30: Discussion of the findings

\begin{tabular}{l|l}
\hline Arroub et al., 2016 & \\
$\boldsymbol{D} ; \boldsymbol{T} ; \boldsymbol{E}$ - No statement
\end{tabular}

\begin{tabular}{l} 
Ruhlandt, 2018 \\
$\boldsymbol{D}$ - EBSCO, Web of Science, ABI Inform Global \\
$\boldsymbol{T}-2003-2017$ \\
$\boldsymbol{E}-1$. Intial search; $N=466$ \\
2. Remove duplicates; $N=407$ \\
3. Absence of keywords in full body; $N=397$ \\
4. Exclusion based on abstract, introduction and conclusion; \\
$N=50$ \\
5. Forward/backward search; $N=62$ \\
\hline Trindade et al., 2017 \\
$\boldsymbol{D}-$ Scopus, Science Direct, and Emerald \\
$\boldsymbol{T}-2012-2017$ \\
$\boldsymbol{E}-1$. Intial search; $N=630$ \\
2. Exclusion based on title and keywords; $N=97$ \\
3. Exclusion based on abstract; $N=47$ \\
4. Exlusion based on full text; $N=25$
\end{tabular}

Method (M) / Restrictions (R) / Focus (F)

$\boldsymbol{M}$ - No statement

$\boldsymbol{R}$ - for $\boldsymbol{A}$ and $\boldsymbol{B}$ : no restrictions in searchfield; including articles, proceedings, books, dotoral theses

$\boldsymbol{F}$ - Urban ecology, sociotechnological and biosociotechnical

$\boldsymbol{M} ; \boldsymbol{R}$ - No statement

$\boldsymbol{F}$ - smart city indicators
$\boldsymbol{M} ; \boldsymbol{R}$ - No statemen

$\boldsymbol{F}$ - Smart city concepts, definitions, models, challenges and opportunities

$\boldsymbol{M}$ - Webster \& Watson, 2002

$\boldsymbol{R}$ - Peer-reviewed journal articles

$\boldsymbol{F}$ - Governance of smart cities
$\boldsymbol{M}$ - Jesson et al., 2011

$\boldsymbol{R}$ - No statement

$\boldsymbol{F}$ - environmental sustainability and smart city concepts 
IADIS International Journal on WWW/Internet

Bibri \& Krogstie, 2017
$\boldsymbol{D}$ - No concrete statement (electronic databases, Google
scholar)
$\boldsymbol{T}$ - 2005 - 2016.
$\boldsymbol{E}$ - No statemant

Meijer \& Bolívar, 2016

$D$ - Web of Science, ScienceDirect, Scopus, EBSCOhost and ABI/INFORM (ProQuest)

$\boldsymbol{T}-1999-2012$

$\boldsymbol{E}$ - 1. Intial search; $N=743$

2. Exclusion based on abstract; $N=80$

3. Exlusion based on full text; $N=51$

Gupta et al., 2019

$D$ - Scopus

$\boldsymbol{T}-2007-2018$

$\boldsymbol{E}$ - 1. Initial search; $N=167$

2. Exclusion based on title and keywords; $N=139$

3. Exclusion based on abstract; $N=96$

4. Exlusion based on full text; $N=86$

Ismagilova et al., 2019

$D$ - Scpous

$\boldsymbol{T}$ - No statement

$\boldsymbol{E}$ - No concrete statement but the search and subsequent review resulted in 104 outputs that formed the literature review for this study.
$\boldsymbol{M}$ - Levy \& Ellis, 2006; Webster

$\&$ Watson, 2002

$\boldsymbol{R}$ - Articles, books, reports,

proceedings, doctoal theses and policy documents

$\boldsymbol{F}$ - Smart city underlying foundations and assumptions,

technological trends and future planning

$\boldsymbol{M}$ - No statement

$\boldsymbol{R}$ - proceedings, books, and doctoral theses

$\boldsymbol{F}$ - Smart city governance

$\boldsymbol{M}$ - Kitchenham, 2004

$\boldsymbol{R}$ - Peer-reviewed research papers

$\boldsymbol{F}$ - Business, management, and accounting

$\boldsymbol{M}$ - Filtered based on author experience

$\boldsymbol{R}$ - Restricted to journals listed in the 'Information Management' category of the Academic Journal Guide 2018 (including: International Arab Journal of Information Technology, Journal of Information Technology Research and International Journal of Information Processing and Management)

$\boldsymbol{F}$ - No statement

Chauhan et al., 2016

D - IEEEXplore, ProQuest, Sciencedirect,

SpringerLink, JSTOR, ACM Digital Library, AIS

eLibrary, EBSCO, Informs, Inderscience, Emerald,

Sage, Wiley Interscience and Google Scholar

$\boldsymbol{T}$ - Papers pubished before February 2016

$\boldsymbol{E}$ - 1. Initial search; $N=310$

2. Exclusion based on title and keywords; $N=190$

3. Exclusion based on abstract; $N=75$

4. Exlusion based on full text; $N=38$
$\boldsymbol{M}$ - Kitchenham \& Charters, 2007

$\boldsymbol{R}$ - Research papers

$\boldsymbol{F}$ - Smart city and big data 


\section{RESEARCH METHODOLOGY}

This study focuses on a review of extant literature on smart cities to explore the current state of the art and future research directions. We used comprehensive search terms in four databases: Web of Science, ACM, IEEE, and EBSCOhost. Our initial approach was to apply an enhanced review method based on the methodologies of Webster and Watson (2002) and Creswell (2012). Thus, a comprehensive literature review should cover all relevant literature on the topic and is not confined to one research methodology, one set of journals, or one geographic region. When applying the search strings "smart city" OR "smart cities" to the databases, we soon faced the problem of a vast amount of literature dealing with the topics of smart cities. For that reason, we developed an algorithm to identify the most relevant sources for full-text reading. As Figure 1 shows, the research process consists of four phases. The first column shows the phases, the second column the single steps conducted in each phase, and the third column the results after each step.

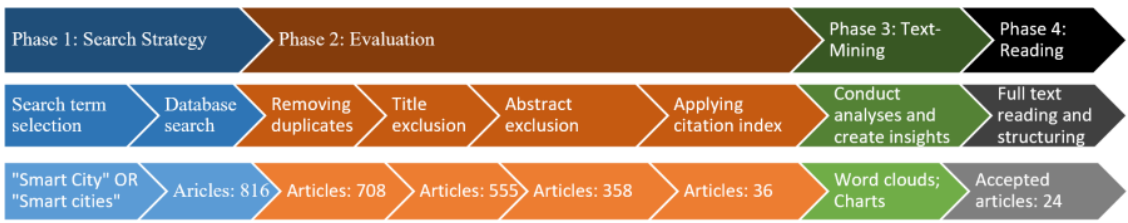

Figure 1. Literature review process

In phase 1 , we were able to identify 816 articles. In phase 2 , after various steps, we gathered 36 articles. In phase 3, we ran corresponding text-mining analyses. In phase 4 , we finally considered 24 articles for the content-related analysis of the six smart city dimensions. The following sections describe each step to give an in-depth look into the methodology of this research.

\section{PHASE 1: SEARCH STRATEGY}

As noted, for a broad search result, we performed the search in four databases. For consistent results, each database was searched with the same selection criteria. We considered only articles published between 2009 and 2019 and written in English. Furthermore, to ensure a high quality of the sources, we considered only peer-reviewed articles by employing Article (Journal)/Proceedings as the document type. Moreover, we searched the article titles and considered only articles that have been cited more than 10 times. In total, we ended up with 816 documents in a list for the full search results. The results of each database were: Web of Science with 472 articles, IEEE with 208, EBSCOhost with 130, and ACM with 6 articles.

\section{PHASE 2: EVALUATION}

Removal of duplicate documents reduced the total number of articles from 816 to 708 . For the remaining 708 articles, we examined their title and abstract to determine whether the focus on smart cities was clearly visible. Subsequently, we excluded 153 articles with this approach based 
IADIS International Journal on WWW/Internet

on the title. Finally, we read the abstracts of these remaining 555 articles, excluded another 197 articles, and ended up with 358 articles in total. The excluded articles either did not clearly focus on smart cities or investigated only technologies and technological implementations. After the exclusion phase, there were still a high number of articles for full-text reading. Therefore, we developed an index to identify the most relevant articles. Such an index needs to consider (a) the total number of citations and (b) the period a specific article is available to other scholars. We created a formula to consider these criteria so that recent articles were not disadvantaged because of their fewer number of citations. Precisely, articles published within the last 12 months received a better ranking. By contrast, articles older than two years received a devaluation for each year. Accordingly, we applied the following formula to the set of 358 articles to determine the most relevant 10 percent of the articles for full-text reading.

where

$$
\text { index }=\frac{\text { number of citations }}{\text { wy }}
$$

$$
w y=\left\{\begin{array}{ll}
\text { year }-0.5 & \text { year }=1 \\
\text { year } & \text { year }=2 \\
\text { year }+\sum_{\mathrm{i}=3}^{\mathrm{n}=\text { year,max }} 0.5 & \text { year }>2
\end{array} \text { for year: } 2019=1 \text { and } 2009=10\right.
$$

\section{PHASE 3: TEXT-MINING APPROACH}

Solely focusing on the 36 most relevant articles (10 percent of 358) would not help answer the research questions of this study. Therefore, we used text-mining to glean insights from both source sets: the full source set with 358 articles and the most relevant source set with 36 articles. With text-mining, we were able to determine the frequency of specific keywords in the abstract of each article and to perform additional analyses. Abstracts have the advantage that they provide the core statement from the perspective of the authors. In addition, the articles are formatted differently and contain sections that can falsify the text-mining analysis, such as related work. Despite the enormous amount of literature, the text-mining approach helped us to cluster the smart city topics in generally accepted smart city dimensions according to Catriona et al. (2014) in order to glean insights about the research structure and popularity.

\subsection{Text-Mining Workflow with RapidMiner}

For text mining, we used RapidMiner Studio 9.5 with the text processing and R-Script extensions (Hofmann \& Klinkenberg, 2014; RapidMiner, 2020). Figure 2 illustrates the implemented text-mining process. Before using RapidMiner, we undertook preparatory work to create the proper data source. Here, we created an Excel file as an input file for RapidMiner that contained every article in separate rows, with relevant information such as title, abstract, publishing year, author, and published journal or conference in separate columns. The creation of the source file was a straightforward step, as we used the reference management software Citavi, which allows exporting of the whole Citavi project as an Excel file (Swiss Academic Software, 2020). 


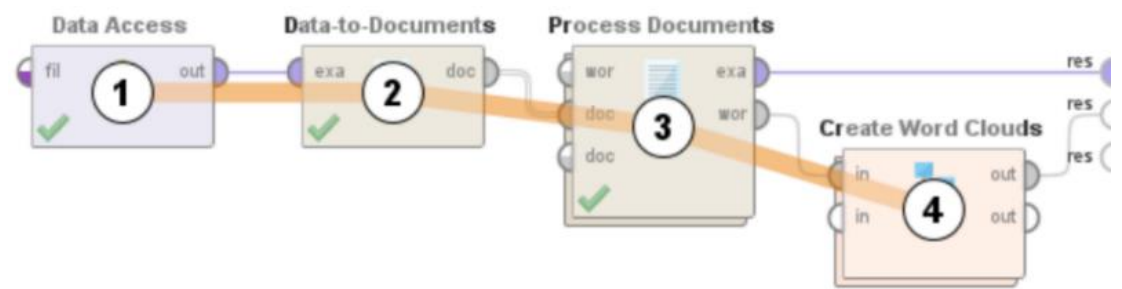

Figure 2. Implemented workflow of the text-mining process in RapidMiner

We divided the workflow in RapidMiner into the four following core steps:

(1) Data Access: RapidMiner provides several predefined nodes for accessing various data sources. In this case, the Read Excel node is used. Parameters such as file location, imported cell range, first row as names, and so on, are to be specified within the node configuration. Thus, this node reads the source file, which was created with Citavi.

(2) Data-to-Documents: For further text processing, the Data-to-Documents node is required. This predefined node transforms the Excel data set into a collection of documents by generating a document for each instance of the data set. Thus, each row of step 1 imported Excel file is converted into a single document.

(3) Process Documents: This is a subprocess that contains common text-mining steps. The predefined node Process Documents provides parameters such as vector creation schema and prune method. In this case, no prune method is chosen, and the term occurrences schema for vector creation is chosen. The term occurrences schema calculates the number of occurrences of a term in each document, which delivers the total number of term occurrences. In this case, the node Process Documents consists of two subprocesses. Figure 3 shows the first layer inside Process Documents. This nested process includes four core nodes.

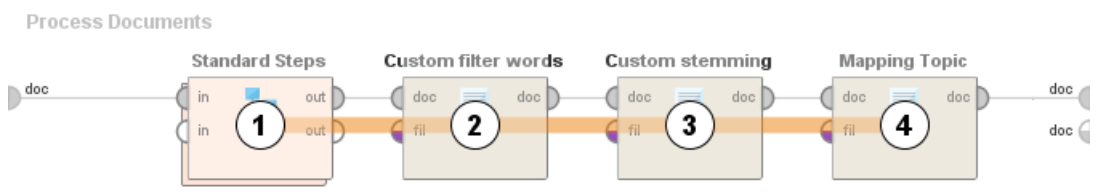

Figure 3. Details of the subprocess Process Documents

Node 2 contains a list of words that are not relevant for the analysis (e.g. "gives", "makes", "thanks", "paper"). Node 3 includes our stemming list. With stemming, we transform the word into its basic form (e.g. "strategies" to "strategy" or "transportation" to "transport"). Node 4 includes the logic for the mapping of subtopics in smart city dimensions. In addition to the custom roles, predefined text-mining steps are required. These are included in node 1, Figure 4 illustrates the subprocess of the Standard Steps in detail.

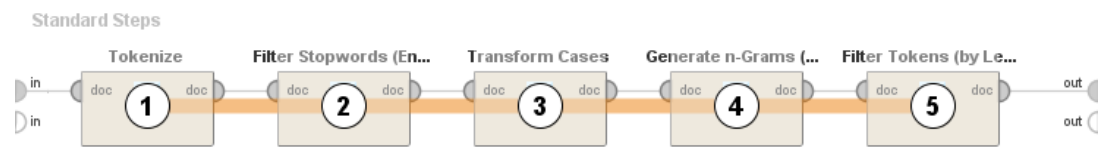

Figure 4. Details of the subprocess Standard Steps 
IADIS International Journal on WWW/Internet

The first node in Figure 4 is tokenization, in non-letters mode. This predefined node splits the text of a document into single tokens. Node 2 filters English stop words from a document by removing every token that equals a word from the predefined list, such as the words "I", "me", "myself", "she" and "him". In node 3, all characters are transformed into lowercase. In node 4 , the n-grams in length 2 are generated. This means that the node generates terms as a series of consecutive tokens of length 2 . For example, the two consecutive tokens "big" and "data" are combined into "big_data". Conclusively, node 4 filters tokens according to their length (in this case, 3 ). Thus, the step Process Documents (Figure 2) is the most extensive step in the applied text-mining workflow. Its outputs are the example set and the word list, which is used in the last step.

(4) Create Word Clouds: The last step takes the created word list of the step Process Documents as input and then builds two-word clouds with a short custom R-script. That means that it is also possible to use this node for other purposes with $\mathrm{R}$.

\subsection{Results}

Figure 5 illustrates the results of the text-mining procedure as word clouds. The left-hand side of Figure 5 is the word cloud based on the whole source set with 358 articles. For better visualization, we restricted the word frequency to at least 10 times. On the right-hand side of Figure 5 is the word cloud based on the most relevant 10 percent of articles (36 in total). We needed to reduce the minimum word frequency to 5 times to gain the best illustration because of the significant smaller word set.
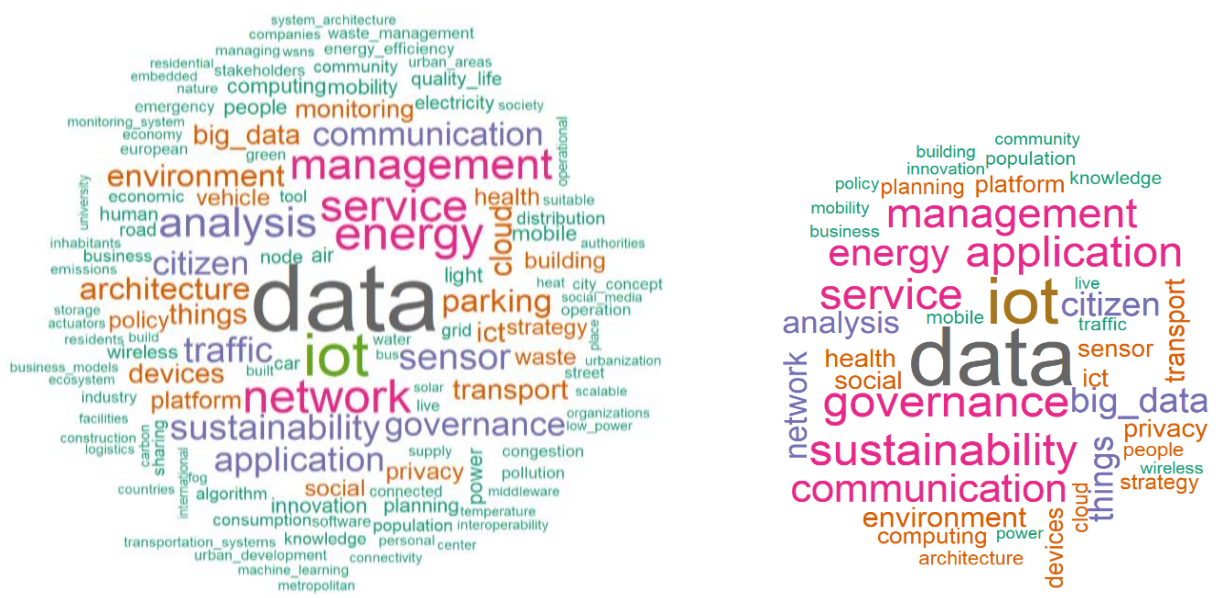

Figure 5. Word clouds (left: 358 articles; right: 36 articles)

Both word clouds show that keywords such as data, IoT, application and communication appear in the list of the most frequently used words in the source sets. By fading out keywords with a strong focus on IT, we show that energy, sustainability, transport and governance are frequently occurring keywords. Furthermore, several terms such as community, population and buildings are still in the word cloud but are less frequent. To evaluate the popularity of the different areas, we mapped each keyword onto smart city dimensions, following the work of 
Catriona et al. (2014) which was published by the European parliament. We do not consider ICT keywords such as "communication", "computing", "WSNS" (wireless sensor network), and "sensor" in this mapping, because these are not clearly assigned to a dimension.

Table 2 shows the mapping of each keyword as well as the frequency from both source sets. The mapping was also realized with RapidMiner by adding a custom-stemming step in the textmining workflow.

Table 2. Mapping of words to smart city dimension

\begin{tabular}{|c|c|c|}
\hline \multicolumn{2}{|c|}{ Dimension } & \multirow{3}{*}{ Terms/Subtopics } \\
\hline \multicolumn{2}{|c|}{ Word frequency } & \\
\hline $\begin{array}{l}\text { All } \\
\text { articles }\end{array}$ & $\begin{array}{l}10 \% \\
\text { articles }\end{array}$ & \\
\hline \multicolumn{2}{|c|}{ Environment } & $\begin{array}{l}\text { energy, sustainability, architecture, environment, waste, building, light, air, } \\
\text { power, road, electricity, grid, consumption, energy_efficiency, pollution, water, } \\
\text { emergency, waste_management, street, green, suitable, built, carbon, emissions, } \\
\text { heat, nature, ecosystem, solar, temperature, build, place, urbanization, centre, } \\
\text { construction, low_power, metropolitan, city_projects }\end{array}$ \\
\hline 1472 & 102 & \\
\hline \multicolumn{2}{|c|}{ Governance } & service, management, governance, policy, strategy, planning, city_concept, \\
\hline 858 & 105 & organizations \\
\hline \multicolumn{2}{|c|}{ Mobility } & traffic, parking, transport, vehicle, mobility, car, \\
\hline 612 & 34 & transportation_systems, bus, logistics \\
\hline \multicolumn{2}{|c|}{ People } & citizen, innovation, people, human, population, european, inhabitants, residents, \\
\hline 405 & 47 & personal, university \\
\hline \multicolumn{2}{|c|}{ Living } & privacy, health, social, quality_life, community, live, urban_areas, \\
\hline 396 & 53 & urban_development, society, social_media, residential \\
\hline \multicolumn{2}{|c|}{ Economy } & economic, sharing, business, knowledge, industry, economy, supply, companies, \\
\hline 209 & 23 & business_models, facilities \\
\hline
\end{tabular}

In summary, Table 2 shows the popularity of each dimension from both source sets. The word frequency field shows how often a word for the corresponding dimension occurs in the respective source sets. The table also shows the mapping of individual terms. So, the ranking in the large source set (358 articles) is as follows: Environment, Governance, Mobility, People, Living, and Economy. In the small source set (36 articles), the ranking is as follows: Governance, Environment, Living, People, Mobility, and Economy. In summary, environment, governance and economy behave similarly in both source sets. However, mobility differs strongly; it is second to last in the small source set and third from the top in the large source set.

Figure 6 (left hand side) provides a deep look into the temporal development of each dimension over the last decade. It can be clearly seen that smart city research has generally increased over the past ten years. It is also evident that the environment dimension is the most popular topic in each year (except 2011). Since we conducted the database query in the third quarter of 2019, there are correspondingly few articles available in 2019, which explains the lower frequency compared to the previous years. The right hand side of Figure 6 shows the frequency of the words occurring in the most relevant 10 percent articles (36 articles in total). Due to the small number of articles in this source set, there are not even one publication in 2009, 2010, and 2013. Therefore, these years are not shown in the chart. 

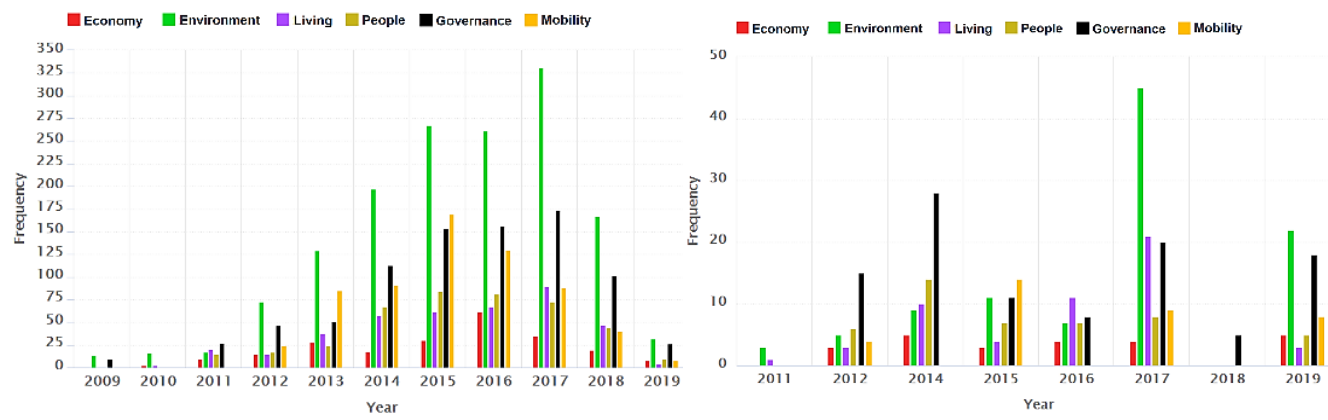

Figure 6. Research development by year (left: 358 artciles; right: 36 articles)

\section{PHASE 4: RELEVANT RESEARCH STREAMS}

This phase provides a content-related list of findings from the identified most relevant articles. The goal is to give insights into relevant research streams and to create a picture of how research is structured around and within each smart city dimension. To achieve this, we analyzed each article in terms of its content. After reading and structuring the 36 articles, we identified 24 sources that suit the smart city dimensions. Table 3 shows the set with 36 articles identified with the formula (described in phase 2). These articles are clustered in the respective dimensions. Some articles are assigned to more than one dimension because they cover more than one dimension, or the topics are overlapping and a separated investigation is not possible. Moreover, there is a cluster for articles that cannot be assigned to at least one dimension. These articles focus on technical issues and implementations (Allam \& Dhunny, 2019; Biswas \& Muthukkumarasamy, 2016; Centenaro et al., 2016; Cruz et al., 2019; Naranjo et al., 2019; Puiu et al., 2016; Zambom Santana et al., 2018) or do not investigate the smart city dimensions (Albino et al., 2015; Colding \& Barthel, 2017; Ferraris et al., 2019; Ismagilova et al., 2019; Kummitha \& Crutzen, 2017).

Table 3. Smart city dimension: Article overview

\begin{tabular}{|c|c|}
\hline $\begin{array}{l}\text { Smart City } \\
\text { Dimension }\end{array}$ & Article [Number of citations; Calculated Index] \\
\hline Environment & $\begin{array}{l}\text { Zanella et al. (2014) [1842; 230]; Jin et al. (2014) [462; 57]; Ahvenniemi et al. (2017) } \\
\text { [137; 39]; Ejaz et al. (2017) [76; 21]; Qi and Shen (2019) [16; 21]; Batagan (2011) } \\
\text { [181; 14]; Sun et al. (2019) [14; 18] }\end{array}$ \\
\hline Governance & $\begin{array}{l}\text { Chourabi et al. (2012) [551; 50]; Batty et al. (2012) [442; 40]; Angelidou (2014) [170; } \\
\text { 21]; Lee and Lee (2014) [158; 19]; Ruhlandt (2018) [50; 25] }\end{array}$ \\
\hline Mobility & $\begin{array}{l}\text { Menouar et al. (2017) [101; 28]; Djahel et al. (2015) [126; 19]; Gharaibeh et al. (2017) } \\
\text { [48; 13]; Qi and Shen (2019) [16; 21] }\end{array}$ \\
\hline People & $\begin{array}{l}\text { Jin et al. (2014) [462; 57]; Chourabi et al. (2012) [551; 50]; Vanolo (2014) [240; 30]; } \\
\text { Schuurman et al. (2012) [224; 20]; Djahel et al. (2015) [126; 19]; Hollands (2015) } \\
\text { [124; 19]; Granier and Hiroko (2016) [89; 17] }\end{array}$ \\
\hline Living & $\begin{array}{l}\text { Solanas et al. (2014) [181; 22]; Zhang et al. (2017) [70; 20]; Al Nuaimi et al. (2015) } \\
\text { [124; 19]; Gharaibeh et al. (2017) [48; 13] }\end{array}$ \\
\hline Economy & $\begin{array}{l}\text { Perera et al. (2014) [328; 41]; Qi and Shen (2019) [16; 21]; Hashem et al. (2016) [126; } \\
\text { 25]; Hollands (2015) [124; 19] }\end{array}$ \\
\hline
\end{tabular}




\begin{abstract}
Not $\quad$ Puiu et al. (2016) [75; 15]; Biswas and Muthukkumarasamy (2016) [82; 16]; Naranjo considered $\quad$ et al. (2019) [13; 17]; Cruz et al. (2019) [13; 17]; Ferraris et al. (2019) [14; 18]; in $\quad$ Zambom Santana et al. (2018) [91; 26]; Centenaro et al. (2016) [198; 39]; Ismagilova dimensions et al. (2019) [69; 92]; Kummitha and Crutzen (2017) [53; 15]; Colding and Barthel (2017) [63; 18]; Allam and Dhunny (2019) [40; 53]; Albino et al. (2015) [381; 92]
\end{abstract}

\title{
7.1 Dimension Smart Environment
}

The reduction of greenhouse gases and the supply with water, energy, and food are some of the primary priorities of cities. ICT can be used to reach these goals (Ahvenniemi et al., 2017; Batagan, 2011). Although the European Commission (2012) defines sustainability, with the help of ICT, as an initial goal for smart cities, the most smart city performance assessment frameworks do not focus enough on the environmental aspects but instead more on economic and social indicators (Ahvenniemi et al., 2017). Some examples of smart environment activities are air quality and noise monitoring (Jin et al., 2014; Zanella et al., 2014), waste management, street lights, and structural health of buildings. All these examples are enabled by ICT (Zanella et al., 2014). With the increasing number of IoT devices, to enable these examples, energy consumption is increasing. Therefore, efficient energy management for IoT in smart cities is a necessity (Ejaz et al., 2017). As in other smart city dimensions, also in the environment dimension, data is an important topic (e.g. probabilistic peak demand estimation with smart meter data) (Sun et al., 2019). Another topic in the smart environment refers to smart buildings. Buildings in cities make up a large part of greenhouse gas emissions. Therefore, Qi and Shen (2019) stress the decarbonization of buildings. To create such emission-light buildings, systems and technologies for energy management, energy efficiency, energy production and storage are required. Another approach in the area of smart buildings is the energy production on-site at buildings (e.g. with photovoltaic systems). Thus, the consumer is a producer as well as a consumer (i.e. "prosumer"). The topic becomes particularly important when surplus energy is fed into the energy market and traded accordingly.

\subsection{Dimension Smart Governance}

Smart cities consist of several components that require strong and intelligent coordination. According to Batty et al. (2012), smart governance is the required superior intelligence that connects all smart city components. First, smart governance aims to improve quality of life by engaging various stakeholders (e.g. citizens, service users). To facilitate this goal, ICT solutions are applied to connect relevant stakeholders and to make the city "smarter". Second, to foster transparency, increasingly more local governments are supplying open data portals to provide public data for interested citizens and professionals. ICT plays a primary role in smart governance (Angelidou, 2014; Batty et al., 2012; Chourabi et al., 2012). According to Batty et al. (2012), a good decision support solution with real time analysis and several simulations are essential. Furthermore, an integrated database for the whole city, sensing and networks, and social media are at the core of smart governance's ICT applications. Although the use of ICT in governance plays an essential role, it is not sufficient alone. A well-balanced combination of ICT, policies, integration of people, norms and moral makes a governance system smart (Angelidou, 2014; Chourabi et al., 2012). 
IADIS International Journal on WWW/Internet

Another function of governance is to mutually manage diverse smart city projects that are involved with various stakeholders. Political support is necessary to cope with this task. Policy must break the legal and regulatory barriers for easy implementation of smart city initiatives. Thus, policy must be able to cope with the functionality of ICT and enable a means for innovations (Chourabi et al., 2012). The government is also responsible for the smart city strategy. Angelidou (2014) describes an approach for strategy development characterized by four decision types. The first is the distinction between the local and national validation level. The second decision type pertains to the urban development stage in terms of whether to help a city get smarter or develop and create a completely new city based on smart city characteristics. The third decision type pertains to which infrastructure to target from the strategy. Angelidou (2014) distinguishes between hard infrastructure (e.g. transportation, waste management, energy) and soft infrastructure (e.g. human capital, education, social life). The fourth decision type is about the economic sector or geographically based reference area. Economic sector means that the strategy aims for a specific economic sector of the city.

According to Lee and Lee (2014), smart city services are also an important element of smart governance. They especially stress the perspective of users and customers of city services and describe a citizen-centric typology framework for smart city services. The dimension of smart governance is particularly broad, and a systematic understanding of its components is not available. Ruhlandt (2018) stresses the need to better understand the components of smart governance, the influence and how to measure them.

\subsection{Dimension Smart Mobility}

The relevance of smart traffic management systems (TMSs) and mobility services is increasing in the economy as well as in citizens' daily lives. Accordingly, one of the main pillars of smart cities is smart mobility (Gharaibeh et al., 2017). Intelligent transportation systems (ITSs) are enablers of smart mobility (Xiong et al., 2012). ITSs (also known as smart TMSs) aim to solve cities' transportation problems by using ICT. Smart TMSs provide services for citizen and road users so that they can benefit directly. Smart mobility services include, for example, route planning and parking management (Djahel et al., 2015). Intelligent TMSs benefit both individual traffic and public transport (Zhang et al., 2017). Moreover, road authorities can use them for road planning and administration, traffic simulations and emergency monitoring (Djahel et al., 2015). Menouar et al. (2017) describes an approach for ITSs that uses drones as monitoring nodes for detecting emergency situations and traffic offenses. Major challenges of smart TMSs are security and privacy aspects because these systems are a point of malicious attacks (Gharaibeh et al., 2017). Furthermore, smart mobility is often considered along with environmental topics (Djahel et al., 2015; Gharaibeh et al., 2017; Qi \& Shen, 2019; Xiong et al., 2012). New mobility concepts are also discussed in the literature. Qi and Shen (2019) discuss the integration of electric vehicles in smart grids and consider their challenges.

\subsection{Dimension Smart People}

In smart cities, individual citizens, groups and communities are supposed to have the opportunity to participate in and co-design their habitat (Chourabi et al., 2012; Granier \& Hiroko, 2016; Hollands, 2015; Schuurman et al., 2012; Vanolo, 2014). Citizen participation ranges from design and implementation to the evaluation and continuous monitoring of diverse 
entities; as such, it can affect several parts of a city positively, such as policy, social justice and education (Granier \& Hiroko, 2016). The research concept of living labs and the usage of ICTs are ways to improve the co-design and innovation process for successful city development (Granier \& Hiroko, 2016; Schuurman et al., 2012). Furthermore, scholars seem to agree that successful development of cities depends strongly on citizen participation (Schuurman et al., 2012). Jin et al. (2014) consider participatory sensing as part of citizen participation. Thus, data collection and sharing are carried out by voluntary citizens instead of the usual sensing paradigms with deployed sensors. This has the advantage of data being collected in different situations and locations at low cost. However, data quality cannot necessarily be guaranteed (Jin et al., 2014). Although ICT facilitates easy participation (e.g. citizens can use their mobile devices for reporting or feedbacking) (Djahel et al., 2015; Jin et al., 2014), citizen- and participation-oriented smart city projects are more relevant than technology-centric projects.

Most smart city initiatives come from either companies or the government, not from the people who live and work in the cities (Hollands, 2015). According to Hollands (2015), ICT should be used in the service of the citizens and not as high-tech quick solutions with the objective of selling profitable products.

\subsection{Dimension Smart Living}

Efficient smart city services, realized with ICT and big data, aim to enhance quality of life. Several scholars have stressed the healthcare and privacy and security themes in this context (Al Nuaimi et al., 2015; Gharaibeh et al., 2017; Solanas et al., 2014; Zhang et al., 2017). An often debated topic within smart living is smart health, which considers several facets in healthcare, including fitness, home care, connected hospitals and early diagnosis or spread of disease in the city (Gharaibeh et al., 2017; Solanas et al., 2014; Zhang et al., 2017). For predictive analysis such as spread of disease in a city, consideration of social media data is a possible approach. On the one hand, medical sensors, wearable devices and medical records data keep track of users' health condition in real time. On the other hand, social networks provide information about users' social contact and interactions. However, collaboration on this information is a major challenge because of heterogeneous data sources and sensibility of the data (Gharaibeh et al., 2017; Zhang et al., 2017). Another school of thought is use of a contextaware network and sensing infrastructure of smart cities. Solanas et al. (2014) define smart health as a combination of mobile health services and cities' sensorics and infrastructure. Thus, for example, real-time data of air pollution and pollination can help inform allergy suffers, or traffic patterns could be controlled for emergency situations. A common challenge, however, of all smart city services is ensuring citizens' privacy. Therefore, to reach broad acceptance, stateof-the-art privacy and security techniques need to be deployed (Gharaibeh et al., 2017; Solanas et al., 2014; Zhang et al., 2017).

\subsection{Dimension Smart Economy}

Data sources such as consumer-connected electronics or sensors, which are distributed through the whole city, constantly generate data, and thus data collection in smart cities is enormous. According to Hashem et al. (2016), data are at the core of novel and optimized business models. Data can be used to detect new patterns for optimizing existing business models and services or to create new data-driven business models (Hashem et al., 2016). To create value from 
IADIS International Journal on WWW/Internet

especially sensor data, Perera et al. (2014) treat the topic sensing as a service model. They describe a four-layer service model that enables business generation, in each layer. Perera et al. (2014) claim that with such a service model, the creation of innovations is easier because the barrier to market entry is lower (e.g. for start-ups). Thus, novel and innovative business models in the whole data life cycle are feasible. According to Hollands (2015) and Hashem et al. (2016), the potential of using data for advertising is enormous. Data can help individualize billboard ads and to create new pricing models (Hollands, 2015; Mulligan \& Olsson, 2013). Social media-based business models are another approach in the context of the smart economy (Hashem et al., 2016). The trend towards privatization of public spaces for business is in evidence, and cities are increasingly becoming the places for corporate advertising.

\section{DISCUSSION AND FURTHER RESEARCH DIRECTIONS}

The main goal of this work was to provide an extensive literature review on smart cities, to answer how relevant research on smart cities is structured and what smart city dimensions are relevant for future research. Although some main dimensions and fields of activity already appear in the literature, there is no analysis on the research popularity of these dimensions. While the environment and governance dimensions are the most popular topics in research over the last decade, the dimension of economy has received less attention from scholars. Furthermore, the analysis of the most relevant 10 percent of articles shows a similar distribution in the upper range of the conducted ranking, but the dimensions of people and living are more in focus than the mobility dimension.

In addition to describing the current state of research, we focus on proposing common ground and further research directions across the different dimensions mentioned in Section 7. This refers to a certain hierarchical structure between the identified research dimensions. A higher-order area for the integration of the different research topics mentioned in Section 7 leads to the discussion of smart city strategies. This is usually incorporated in the dimension of smart governance (Angelidou, 2014; Ruhlandt, 2018). Therefore, smart governance and the broad discussion around smart city strategies, multidisciplinarity, smart city architecture, and IT governance might be viewed as a starting point and meta model for current research. An important part of this discussion is linked to the demand for reference architectures for smart cities. Such architectures are usually divided in the subdomains of 1) technology, 2) data, and 3) services (Hashem et al., 2016; Perera et al., 2014; Ruhlandt, 2018). Moreover, reference architectures describe how different initiatives, e.g. in the context of environment, mobility or living are integrated within a single city or area, strategic context, and data structure.

Adopting this perspective, the subdomain of technology is present in multiple research dimensions. For instance, in a smart environment future research might consider energy-efficient mechanisms for software-defined IoT solutions that can provide scalable and context-aware data and services. Furthermore, energy efficiency and complexity of security protocols are crucial aspects for the practical implementation of IoT-based services. An important research stream in the dimension of smart mobility includes active vehicle safety and intelligent vehicles. Core developments in this area are mainly driven by perceptions of the environment, intelligent control, and active collision avoidance. Perceptions of the driving environment entail identifying driving conditions and locations, lanes, traffic lights, vehicles 
and pedestrians, and so on. Emerging technologies can include security warnings, auxiliary driving, and active collision avoidance (Xiong et al., 2012).

In the subdomain of data corresponding strategies need to elaborate in aspects like data integration, data analysis, and data-based simulations. Further research might focus on urban data portals and the integration of data between different dimensions of smart cities. Such an approach is increasingly resulting in complexity, thus leading to the need for statistical mechanics or cognitive systems to simulate smart city solutions. Thus, the science and art of urban simulation will play a major role in future research (Batty et al., 2012). Such a data integration might consider mobility data, environmental data, but also private data in the area of smart living. State-of-the-art security and privacy techniques are essential for intelligent healthcare. Without effective protections, users may not be willing to share their health data with others, leading to challenges in infection analysis (Zhang et al., 2017).

Finally, services, business and operating models need further development in the third subdomain of a corresponding reference architecture. This requires a better link among the architectural views of IT, communication networks and the provision of services. Particularly, further research needs to be conducted in the area of smart city business models. It is essential for business models to generate trust in smart city systems. Doing so requires approaches in which the end users have direct control over their data streams, enabling both top-down and bottom-up approaches to civic engagement (Mulligan \& Olsson, 2013). Therefore, governance models of the future will be driven by citizens, communities and their collaboration. As such, smart cities need to develop web-based and interactive context that enables a wider range of citizens to understand and contribute to the design of the city (Lee \& Lee, 2014).

However, we noted two limitations of this study. The structuring in the dimensions governance, mobility, living, people, environment, and economy might be considered as one of the limitation of this study, since some subtopics are very extensive that they could be considered as own dimension. For example, it is challenging to treat urban planning only as a subtopic of governance. Furthermore, the diversity of smart cities makes it difficult to define the main smart city dimensions finally. The second limitation of this work is related to the manual specification of a cluster logic for text mining. The considered dimensions are only one relevant approach for clustering; other approaches are also conceivable. For example, machine learning might be adopted for data-driven clustering in structured literature reviews (e.g., the application of k-means clustering approaches in wordlists).

\section{CONCLUSION}

The results of this review allowed us to establish the status and structure of the smart city research of the last decade, and highlight several research directions in each smart city dimension. To sum up, the analysis of the most relevant articles in the area of smart cities shows that integrated ICT solutions play an enabling role in all "smart" solutions in each dimension. Furthermore, the relevance of data is especially stressed in the articles on smart economy, smart environment, and smart mobility. We also show the importance of data in the context of smart cities in the word clouds in Figure 5. Another insight is that the dimensions are not completely isolated from one another; in contrast, the different dimensions need to be integrated in a mutual reference architecture. 
IADIS International Journal on WWW/Internet

We consider that our work provides a form of grounding for further research and practice. The findings enable researchers to understand the research structure of smart cities better and helps on focusing their work into existing gaps in a specific dimension. Furthermore, practitioners can use our findings to develop strategies and projects purposefully.

\section{REFERENCES}

Ahvenniemi, H., Huovila, A., Pinto-Seppa, I., \& Airaksinen, M. (2017). What are the differences between sustainable and smart cities? Cities, 60, 234-245.

Al Nuaimi, E., Al Neyadi, H., Mohamed, N., \& Al-Jaroodi, J. (2015). Applications of big data to smart cities. Journal of Internet Services and Applications, 6, Article 25.

Albino, V., Berardi, U., \& Dangelico, R. M. (2015). Smart Cities: Definitions, Dimensions, Performance, and Initiatives. Journal of Urban Technology, 22(1), 3-21.

Allam, Z., \& Dhunny, Z. A. (2019). On big data, artificial intelligence and smart cities. Cities, 89, 80-91.

Angelidou, M. (2014). Smart city policies: A spatial approach. Cities, 41(1), 3-11.

Arroub, A., Zahi, B., Sabir, E., \& Sadik, M. (2016). A literature review on Smart Cities: Paradigms, opportunities and open problems. IEEE International Conference on Wireless Networks and Mobile Communications (WINCOM), 180-186.

Batagan, L. (2011). Smart Cities and Sustainability Models. Informatica Economica, 15(3), 80-87.

Batty, M., Axhausen, K. W., Giannotti, F., Pozdnoukhov, A., Bazzani, A., Wachowicz, M., Ouzounis, G., \& Portugali, Y. (2012). Smart cities of the future. The European Physical Journal Special Topics, 214(1), 481-518

Bibri, S. E., \& Krogstie, J. (2017). Smart sustainable cities of the future: An extensive interdisciplinary literature review. Sustainable Cities and Society, 31, 183-212.

Biswas, K., \& Muthukkumarasamy, V. (2016). Securing Smart Cities Using Blockchain Technology. Proceedings of 2016 IEEE 18th International Conference on High Performance Computing and Communications; IEEE 14th International Conference on Smart City; IEEE 2nd International Conference on Data Science and Systems (Hpcc/Smartcity/Dss), 1392-1393.

Bozkurt, Y., Braun, R., Rossmann, A., \& Hertweck, D. (2020). The Advent of Smart Cities: Status Quo and Future Research Directions. 6th International Conference on Connected Smart Cities (MCCSIS2020), 105-116.

Caragliu, A., Del Bo, C., \& Nijkamp, P. (2011). Smart Cities in Europe. Journal of Urban Technology, $18(2), 65-82$.

Catriona, M., Cochrane, G., Cave, J., Millard, J., Pederson, J. K., Kåre, R., Liebe, A., Wissner, M., Massnik, R., \& Kotternik, B. (2014). Mapping Smart cities in the EU: Directorate-General for Internal Policies. Policy Department A: Economic and Scientific Policy. European Parlament.

Centenaro, M., Vangelista, L., Zanella, A., \& Zorzi, M. (2016). Long-range communications in unlicensed bands: the rising stars in the IoT and smart city scenarios. IEEE Wireless Communications, 23(5), 60-67.

Chauhan, S., Agarwal, N., \& Kar, A. K. (2016). Addressing big data challenges in smart cities: a systematic literature review. Info, 18(4), 73-90.

Chourabi, H., Nam, T., Walker, S., Gil-Garcia, J. R., Mellouli, S., Nahon, K., Pardo, T. A., \& Scholl, H. J. (Eds.) (2012). Understanding Smart Cities: An Integrative Framework. 2012 45th Hawaii International Conference on System Sciences.

Colding, J., \& Barthel, S. (2017). An urban ecology critique on the "Smart City" model. Journal of Cleaner Production, 164, 95-101. 
Creswell, J. W. (2012). Educational research: Planning, conducting, and evaluating quantitative and qualitative research (Fourth Indian edition). PHI Learning Private Limited.

Cruz, P., Couto, R. S., \& Costa, L. H. M.K. (2019). An algorithm for sink positioning in bus-assisted smart city sensing. Future Generation Computer Systems, 93, 761-769.

Djahel, S., Doolan, R., Muntean, G., \& Murphy, J. (2015). A Communications-Oriented Perspective on Traffic Management Systems for Smart Cities: Challenges and Innovative Approaches. IEEE Communications Surveys \& Tutorials, 17(1), 125-151.

Ejaz, W., Naeem, M., Shahid, A., Anpalagan, A., \& Jo, M. (2017). Efficient Energy Management for the Internet of Things in Smart Cities. IEEE Communications Magazine, 55(1), 84-91.

European Commission (2012). Smart Cities and Communities - European Innovation Partnership.

Ferraris, A., Erhardt, N., \& Bresciani, S. (2019). Ambidextrous work in smart city project alliances: unpacking the role of human resource management systems. The International Journal of Human Resource Management, 30(4), 680-701.

Gharaibeh, A., Salahuddin, M. A., Hussini, S. J., Khreishah, A., Khalil, I., Guizani, M., \& Al-Fuqaha, A. (2017). Smart Cities: A Survey on Data Management, Security, and Enabling Technologies. IEEE Communications Surveys \& Tutorials, 19(4), 2456-2501.

Giffinger, R., Gudrun, H., Gudrun, \& Haindlmaier, G. (2010). Smart cities ranking: An effective instrument for the positioning of the cities. ACE: Architecture, City and Environment, 4(12), 7-26.

Granier, B., \& Hiroko, K. (2016). How are citizens involved in smart cities? Analysing citizen participation in Japanese "Smart Communities". Information Polity: The International Journal of Government \& Democracy in the Information Age, 21(1), 61-76.

Gupta, P., Chauhan, S., \& Jaiswal, M. P. (2019). Classification of Smart City Research - a Descriptive Literature Review and Future Research Agenda. Information Systems Frontiers, 21(3), 661-685.

Hashem, I. A. T., Chang, V., Anuar, N. B., Adewole, K., Yaqoob, I., Gani, A., Ahmed, E., \& Chiroma, H. (2016). The role of big data in smart city. International Journal of Information Management, 36(5), $748-758$.

Hofmann, M., \& Klinkenberg, R. (2014). Rapidminer: Data mining use cases and business analytics applications. Chapman \& Hall / CRC data mining and knowledge discovery series. CRC Press.

Hollands, R. G. (2015). Critical interventions into the corporate smart city. Cambridge Journal of Regions, Economy and Society, 8(1), 61-77.

Ismagilova, E., Hughes, L., Dwivedi, Y. K., \& Raman, K. R. (2019). Smart cities: Advances in research-An information systems perspective. International Journal of Information Management, 47, 88-100.

Jin, J., Gubbi, J., Marusic, S., \& Palaniswami, M. (2014). An Information Framework for Creating a Smart City Through Internet of Things. IEEE Internet of Things Journal, 1(2), 112-121.

Kummitha, R. K. R., \& Crutzen, N. (2017). How do we understand smart cities? An evolutionary perspective. Cities, 67, 43-52.

Lee, J., \& Lee, H. (2014). Developing and validating a citizen-centric typology for smart city services. Government Information Quarterly, 31(1), 93-105.

Lombardi, P., Giordano, S., Farouh, H., \& Yousef, W. (2012). Modelling the smart city performance. Innovation: The European Journal of Social Science Research, 25(2), 137-149.

Meijer, A., \& Bolívar, M. P. R. (2016). Governing the smart city: a review of the literature on smart urban governance. International Review of Administrative Sciences, 82(2), 392-408.

Menouar, H., Guvenc, I., Akkaya, K., Uluagac, A. S., Kadri, A., \& Tuncer, A. (2017). UAV-Enabled Intelligent Transportation Systems for the Smart City: Applications and Challenges. IEEE Communications Magazine, 55(3), 22-28.

Mori, K., \& Christodoulou, A. (2012). Review of sustainability indices and indicators: Towards a new City Sustainability Index (CSI). Environmental Impact Assessment Review, 32(1), 94-106. 
IADIS International Journal on WWW/Internet

Mulligan, C. E. A., \& Olsson, M. (2013). Architectural Implications of Smart City Business Models: An Evolutionary Perspective. IEEE Communications Magazine, 51(6), 80-85.

Naranjo, P. G. V., Pooranian, Z., Shojafar, M., Conti, M., \& Buyya, R. (2019). FOCAN: A Fog-supported smart city network architecture for management of applications in the Internet of Everything environments. Journal of Parallel and Distributed Computing, 132, 274-283.

Perera, C., Zaslavsky, A., Christen, P., \& Georgakopoulos, D. (2014). Sensing as a service model for smart cities supported by Internet of Things. Transactions on Emerging Telecommunications Technologies, 25(1), 81-93.

Puiu, D., Barnaghi, P., Tönjes, R., Kümper, D., Ali, M. I., Mileo, A., Xavier Parreira, J., Fischer, M., Kolozali, S., Farajidavar, N., Gao, F., Iggena, T., Pham, T., Nechifor, C., Puschmann, D., \& Fernandes J. (2016). CityPulse: Large Scale Data Analytics Framework for Smart Cities. IEEE Access, 4, $1086-1108$

Purnomo, F., \& Prabowo, H. (2016). Smart City Indicators: A Systematic Literature Review. Journal of Telecommunication, Electronic and Computer Engineering, 8(3), 161-164.

Qi, W., \& Shen, Z.-J. M. (2019). A Smart-City Scope of Operations Management. Production \& Operations Management, 28(2), 393-406.

RapidMiner. (2020). RapidMiner Studio (Version 9.5) [Computer software]. RapidMiner.

Ruhlandt, R. W. S. (2018). The governance of smart cities: A systematic literature review. Cities, 81, $1-23$.

Schuurman, D., Baccarne, B., Marez, L. de, \& Mechant, P. (2012). Smart Ideas for Smart Cities: Investigating Crowdsourcing for Generating and Selecting Ideas for ICT Innovation in a City Context. Journal of Theoretical \& Applied Electronic Commerce Research, 7(3), 49-62.

Solanas, A., Patsakis, C., Conti, M., Vlachos, I., Ramos, V., Falcone, F., Postolache, O., Perez-martinez, P., Pietro, R., Perrea, D., \& Martinez-Balleste, A. (2014). Smart health: A context-aware health paradigm within smart cities. IEEE Communications Magazine, 52(8), 74-81.

Sun, M., Wang, Y., Strbac, G., \& Kang, C. (2019). Probabilistic Peak Load Estimation in Smart Cities Using Smart Meter Data. IEEE Transactions on Industrial Electronics, 66(2), 1608-1618.

Swiss Academic Software. (2020). Citavi (Version 6) [Computer software]. Swiss Academic Software.

Trindade, E. P., Hinnig, M. P. F., da Costa, E. M., Marques, J. S., Bastos, R. C., \& Yigitcanlar, T. (2017). Sustainable development of smart cities: a systematic review of the literature. Journal of Open Innovation: Technology, Market, and Complexity, 3(1), 234.

Vanolo, A. (2014). Smartmentality: The Smart City as Disciplinary Strategy. Urban Studies, 51(5), 883-898.

Webster, R., \& Watson, R. (2002). Analyzing the Past to Prepare for the Future: Writing a Literature Review. MIS Quarterly, 26(2), 13-23.

Xiong, Z., Sheng, H., Rong, W., \& Cooper, D. E. (2012). Intelligent transportation systems for smart cities: a progress review. Science China Information Sciences, 55(12), 2908-2914.

Zambom Santana, E. F., Chaves, A. P., Gerosa, M. A., Kon, F., \& Milojicic, D. S. (2018). Software Platforms for Smart Cities: Concepts, Requirements, Challenges, and a Unified Reference Architecture. ACM Computing Surveys, 50(6).

Zanella, A., Bui, N., Castellani, A., Vangelista, L., \& Zorzi, M. (2014). Internet of Things for Smart Cities. IEEE Internet of Things Journal, 1(1), Article 78, 22-32.

Zhang, K., Ni, J., Yang, K., Liang, X., Ren, J., \& Shen, X. (2017). Security and Privacy in Smart City Applications: Challenges and Solutions. IEEE Communications Magazine, 55(1), 122-129. 